\title{
Sleep quality and academic performance among Nigerian undergraduate students
}

\author{
Champion Tobi Seun-Fadipe* and Kolawole Samuel Mosaku \\ Department of Mental Health, Obafemi Awolowo University Teaching Hospitals, Ile-Ife, Osun State, Nigeria
}

\begin{abstract}
Objectives: The study assessed sleep quality among the entire student population of a Nigerian University and its association with academic performance and perceived stress. It also identified factors that may be associated with poor sleep quality and academic performance among the students.

Methods: It was a cross-sectional descriptive study which employed a multistage sampling method to recruit the study participants. A self-administered instrument including a questionnaire on Sociodemographic characteristics, an item of question assessing the Cumulative Grade Point Average (CGPA), Pittsburgh Sleep Quality Index (PSQI) and Perceived Stress Scale (PSS-10) was administered to assess the socio-demographics, academic performance, sleep quality and level of perceived stress.

Results: About one out of every two students had poor sleep quality (49.5\%). The academic performance of students with good sleep quality was significantly better than those with poor sleep quality $(\mathrm{t}=4.39, \mathrm{p}<0.01)$ while the level of perceived stress level for students with poor sleep quality was also significantly higher than those with good sleep quality $(\mathrm{t}=2.80, \mathrm{p}<0.01)$. In the population studied, sleep quality was an independent predictor of their academic performance.
\end{abstract}

Conclusion: This study further emphasizes the relationship between sleep quality and academic performance of undergraduate student.

\section{Introduction}

Sleep is an important physiological process that is essential for human survival [1]. Among the most important functions of sleep is the enhancement of optimal cognitive functioning such as attention [2], insight [3], decision-making [4], speech [5], and most notably learning and memory [6-8], factors which are very key for efficient academic performance of undergraduate students. The quality of sleep is measured along quantitative and qualitative dimensions. The quantitative component includes the duration of sleep while the qualitative component is a subjective measure of the depth and feeling of restfulness upon awakening [9]. Sleep quality has been documented to be a predictor of academic performance [10-12].

The demand for high academic performance among University students can also be associated with stress. Perceived stress is the feeling or thought that an individual has about how much stress they are under at a given point in time or over a given time period [13]. In an academic environment, some factors that have been associated with stress include high parental expectations [14], frequency of examinations, vastness of the academic curriculum [15] and anxiety about employment opportunities in the future [14]. Perceived stress has also been shown to affect sleep pattern and sleep quality of undergraduate students [16].

One model framework that can probably explain stress among undergraduate students is the transactional model of stress which suggests that the level of stress experienced in the form of thoughts, feelings, emotions and behavior as a result of external stressors, depends on appraisals of the situation which involves a judgement about whether internal or external demands (within the academic environment) exceed resources and ability to cope when demands exceed resources [17]. A significant association has been reported between stress and academic performance. Too much stress leads to poor academic performance [18]. It has also been associated with significant psychological morbidity which can potentially also reduce academic performance [19].

Among Nigerian undergraduate students, only one study [20] has been done to evaluate the association between sleep quality and academic performance. There is a need to examine this association among the entire student population as the previous study only focused on the pharmacy students in the University. This study aims to assess sleep quality among the entire student population of a Nigerian University and its association with perceived stress and academic performance. It also identifies factors that may be associated with poor sleep quality and academic performance among the students.

\section{Methods}

\section{Study design and participants}

A cross-sectional descriptive study was conducted amongst undergraduate students of Obafemi Awolowo University, Ile-Ife who are resident within the school environment. Students who were acutely ill and those with sensory deficits were excluded from the study. Students with severe cognitive deficits were also excluded. follows:

The sample size was estimated using the Kish formula [21], as

Correspondence to: Seun-Fadipe Champion Tobi, Department of Mental Health, Obafemi Awolowo University Teaching Hospitals, Ile-Ife, Osun State, Nigeria, Tel: +2348037692418,+2348052557153, E-mail- heavenlychamp@gmail.com

Key words: Sleep, perceived stress, university students, sub-Saharan Africa

Received: August 24, 2017; Accepted: September 22, 2017; Published: September 25, 2017 


$$
\mathrm{n}=\mathrm{z}^{2} \mathrm{p}(1-\mathrm{p}) \div \mathrm{d}^{2}
$$

Where $\mathrm{n}=$ required sample size, $\mathrm{z}=$ confidence level at $95 \%$ (standard value of 1.96),

$\mathrm{p}=$ estimated prevalence rate, and $\mathrm{d}=$ margin of error at $5 \%$ (standard value of 0.05 ).

$\mathrm{n}=1.96^{2} 0.325(1-0.325) \div 0.05^{2}$ using $32.5 \%$ from a previous study [22] as the best estimate of poor sleep quality among medical students at a Nigerian University, a minimum sample size of 337 was calculated and used for the study.

A multistage sampling method by means of probability proportionate to size was used to recruit the study participants. Participants were recruited via the halls of residence within the school premises. Two male and two female halls were selected randomly, and the number of participants per hall was determined by proportional sampling from the odd-numbered blocks in the halls. Participants were then recruited until the sample from each hall was complete.

Regarding ethical considerations, the study protocol was presented for approval by Health Research Ethics Committee, Institute of Public Health, Obafemi Awolowo University, Ile-Ife. The study participants were chosen after their informed consent was obtained to participate. The researchers approached each student by giving an overview of the study, explained the procedures and reassured the subjects that their privacy would be maintained, and that any obtained information would be strictly confidential.

\section{Measurements}

\section{Sociodemographic questionnaire}

A semi structured Socio-demographic data schedule was designed to elicit information on variables such as age, gender, year of study, marital status etc.

\section{Academic performance}

Academic performance was assessed by asking participants about their Cumulative Grade Point Average (CGPA). Participants provided their CGPA for the last semester prior to the study period. In the University studied, the CGPA ranged from 1.00 to 5.00 points. The points between $4.50-5.00$ are categorized as First Class, 3.50-4.49 as Second Class Upper, 2.50-3.49 as Second Class Lower and 1.50-2.49 as Third Class. Grade points lower than 1.50 is categorized as Pass.

\section{Pittsburgh Sleep Quality Index (PSQI)}

The Pittsburgh Sleep Quality Index (PSQI) is a self-rated instrument that measures sleep quality over a month period [9]. The index is comprised of 19 items, which are combined to form 7 component scores. The components include subjective sleep quality, sleep latency, sleep duration, habitual sleep efficiency, sleep disturbances, use of sleep medication, and daytime dysfunction. Each component score has a range of 0 (no difficulty) to 3 (severe difficulty). The 7 component scores are added to yield a global score, which ranges from 0 to 21. A global PSQI score less than or equal to 5 indicates good sleep quality, whereas a score greater than 5 is considered to represent poor sleep quality [23]. This psychometric instrument has been previously validated among a student population in Nigeria [23].

\section{Perceived Stress Scale (PSS)}

The Perceived Stress Scale (PSS) was developed by Sheldon Cohen to measure the degree to which individuals appraise life events over the past month as being stressful [24]. Although, there are three versions of the PSS: with 4,10, and 14 items respectively. The 10-item version was used in this study. Each item was scored using a 5-point rating scale from 0 (never) to 4 (very frequent), and scores of items $4,5,7$ and 8 were reversed. The PSS is not a diagnostic instrument, so there are no cut-offs to determine perceived stress and comparisons are only allowed between individuals. Higher scores correspond to higher perceived stress (linear relation).

The perceived stress level was analysed by quartiles of perceived stress as done in a previous study [25]. The first quartile represented the students not/less stressed, with a PSS score of less than 10; the second quartile had a PSS score of 10 to 15, the third quartile had a PSS score of 16 to 20 , and the fourth quartile represented highly stressed students with a PSS score of more than 20 . The instrument has been previously used in Nigeria [26].

\section{Analysis}

Data were analyzed using the Statistical Package for Social Sciences (SPSS, Chicago, IL) version 20. The data were summarized using descriptive statistics such as proportion, frequency and mean. Independent student $t$ tests, Analysis of variance (ANOVA) and Pearson correlation analyses were used to explore associations and relationships between variables. Binary logistic regression was used to determine the predictors of poor sleep quality while linear regression was used to determine the predictors of academic performance. A $\mathrm{p}$-value of $<0.05$ was considered statistically significant in all cases.

\section{Results}

Of the 337 students recruited for the study, 317 returned a completely-filled questionnaire, giving a response rate of $94.1 \%$. Table 1 summarized the results of the demographic characteristics as well as academic performance and perceived stress. The age range of the participants was between 18 and 35 years [mean age $(\mathrm{SD})=22.2(2.9)$ ], and $54.9 \%$ were male. Majority (97.2\%) of the students were single. About 2 out of every 10 students were engaged in a part-time paid employment to supplement their financial resources. The mean sleep duration of the student population studied was about 6 hours while the students usually go to bed around $11 \mathrm{pm}$.

Furthermore, 157 (49.5\%) students had poor sleep quality (PSQI score $>5)$. The academic performance of the students was more than average [Mean $(\mathrm{SD})=3.63(0.62)]$ while the perceived stress score indicated moderate to severe level of stress [Mean (SD) = $17.06(4.96)]$.

\section{Relationship between sleep quality, academic performance and perceived stress}

Table 2 shows that the academic performance of students with good sleep quality was significantly better than those with poor sleep quality $(p<0.01)$. The stress level for students with poor sleep quality was also significantly higher than those with good sleep quality $(p<0.01)$.

The correlational relationship is described in Table 3. The academic performance improved as the PSQI score reduced $(p<0.01)$. This means as the sleep quality became better, the academic performance improved. Similarly, as the stress level increased, the poorer the sleep quality. However, perceived stress did not have any significant relationship with academic performance $(p=0.88)$.

\section{Factors associated with poor sleep quality}

The demographic variables and other factors were explored for association with sleep quality (Table 4). Out of all the factors studied, 
Table 1. Sociodemographic and sleep-related variables

\begin{tabular}{|c|c|c|}
\hline Variables & Frequency $n=317$ & Percentage $(\%)$ \\
\hline \multicolumn{3}{|l|}{ Age (in years) } \\
\hline $18-20$ & 111 & 35 \\
\hline $21-23$ & 115 & 36.3 \\
\hline$>23$ & 91 & 28.7 \\
\hline \multicolumn{3}{|l|}{ Gender } \\
\hline Male & 174 & 54.9 \\
\hline Female & 143 & 45.1 \\
\hline \multicolumn{3}{|l|}{ Marital status } \\
\hline Single & 308 & 97.2 \\
\hline Married & 9 & 2.8 \\
\hline \multicolumn{3}{|l|}{ Year of study } \\
\hline $1^{\text {st }}$ and $2^{\text {nd }}$ year & 95 & 30 \\
\hline $3^{\text {rd }}$ year & 59 & 18.6 \\
\hline $4^{\text {th }}$ year & 120 & 37.9 \\
\hline $5^{\text {th }}$ and $6^{\text {th }}$ year & 43 & 13.6 \\
\hline \multicolumn{3}{|l|}{ Number of courses } \\
\hline$\leq 5$ & 97 & 30.6 \\
\hline$>6$ & 220 & 69.4 \\
\hline \multicolumn{3}{|l|}{ Carrying over any courses } \\
\hline Yes & 30 & 9.5 \\
\hline No & 287 & 90.5 \\
\hline \multicolumn{3}{|l|}{ Part time employment } \\
\hline Yes & 55 & 17.4 \\
\hline No & 262 & 82.6 \\
\hline \multicolumn{3}{|l|}{ Sleep duration (hours) } \\
\hline Mean $(\mathrm{SD})$ & $5.9(2.49)$ & \\
\hline \multicolumn{3}{|l|}{ Routine bed time (hours) } \\
\hline Mean $(\mathrm{SD})$ & $23.34(1.41)$ & \\
\hline \multicolumn{3}{|l|}{$\begin{array}{c}\text { Academic performance } \\
\text { (CGPA) }\end{array}$} \\
\hline Mean $(\mathrm{SD})$ & $3.63(0.62)$ & \\
\hline First Class & 23 & 7.3 \\
\hline Second Class Upper & 182 & 57.4 \\
\hline Second Class Lower & 95 & 30 \\
\hline Third Class & 17 & 5.4 \\
\hline \multicolumn{3}{|l|}{ Sleep Quality (PSQI) } \\
\hline Mean $(\mathrm{SD})$ & $5.95(3.13)$ & \\
\hline Good $($ Score $\leq 5)$ & 160 & 50.5 \\
\hline Poor $($ score $>5)$ & 157 & 49.5 \\
\hline \multicolumn{3}{|l|}{ Perceived Stress (PSS) } \\
\hline Mean $(\mathrm{SD})$ & $17.06(4.96)$ & \\
\hline
\end{tabular}

Table 2. Mean differences in academic performance and perceived stress based on sleep quality

\begin{tabular}{|c|c|c|c|c|c|}
\hline & $\begin{array}{c}\text { Good Sleep } \\
\text { Quality }\end{array}$ & $\begin{array}{c}\text { Poor Sleep } \\
\text { Quality }\end{array}$ & Statistics & $\mathrm{df}$ & P value \\
\hline $\begin{array}{c}\text { Mean CGPA } \\
\text { (SD) }\end{array}$ & $3.78(0.58)$ & $3.49(0.63)$ & $\mathrm{t}=4.39$ & 315 & $<0.01$ \\
\hline $\begin{array}{c}\text { Mean } \\
\text { Perceived } \\
\text { Stress (SD) }\end{array}$ & $16.29(5.29)$ & $17.83(4.51)$ & $\mathrm{t}=-2.80$ & 315 & $<0.01$ \\
\hline
\end{tabular}

Table 3. Correlation between sleep quality, academic performance and perceived stress

\begin{tabular}{|c|c|c|c|}
\hline & PSQI Global Score & CGPA & Perceived Stress \\
\hline PSQI Global Score & 1 & $-0.30^{* *}$ & $0.15^{* *}$ \\
\hline CGPA & & 1 & -0.01 \\
\hline Perceived Stress & & & 1 \\
\hline
\end{tabular}

**Correlation is significant at the 0.01 level the gender $(p=0.02)$, year of study $(p<0.01)$, extra courses carried over from previous semester $(p=0.04)$, part-time employment $(p<0.01)$ and mean sleep duration $(p=0.01)$ had significant association with sleep quality. Female students had better sleep quality when compared with their male counterparts while sleep quality was observed to be poorest among students in their $5^{\text {th }}$ and $6^{\text {th }}$ year of study. Students who incorporated failed courses from the previous semester into their current academic schedule had poorer sleep quality than students who passed all their courses in the previous semester while students who engaged in part-time job had poorer sleep quality when compared with students who did not. Also, as mean sleep duration increased, the sleep quality became poorer.

Logistic regression was performed to ascertain the effects of the factors with significant associations on the likelihood that the study participants will have poor sleep quality (Table 5). The logistic regression model was statistically significant, $\chi^{2}(\mathrm{df})=59.58(13), p<0.01$. The model explained $17.1 \%$ (Cox and Snell $\mathrm{R}^{2}$ ) to $22.8 \%$ (Nagelkerke $\mathrm{R}^{2}$ ) of the variance in poor sleep quality and correctly classified $67.8 \%$ of cases. The students in their $4^{\text {th }}$ year were less likely than those in the first and second year to have poor sleep quality $(p<0.01)$. Moreover, students with part-time employment were 2.6 times more likely to have poor sleep quality compared with those without a part-time employment $(p<0.01)$. Furthermore, the odds of having poor sleep quality increased as the academic performance became poorer and the perceived stress level increased. In addition, for every unit change in sleep duration the log odds of having poor sleep quality increased by $0.764(p=0.01)$.

\section{Factors associated with academic performance}

Table 4 also shows the demographic and sleeps habit-related factors analyzed for significant association with academic performance. The gender $(p<0.01)$ and extra courses carried over from previous semester $(p<0.01)$ had significant association with academic performance. Female students had better academic performance than male students. In addition, students who carried over failed courses from previous semester had poorer academic performance than those who passed all their courses in the previous semester.

Linear regression was performed to ascertain the effects of the factors with significant associations as predictors of academic performance (Table 5). The regression model statistically predicted the outcome variable $[\mathrm{F}(3,313)=17.04, p<0.01]$ and it explained $13.2 \%$ of the variance in academic performance. For every one-unit change in the number of extra courses carried over from previous semester, academic performance increased by $0.19(p<0.01)$. In addition, for every unit increase in the PSQI score, academic performance decreased by $0.05(p<0.01)$. This implies that academic performance improved as the sleep quality increased. This is because sleep quality becomes better as the PSQI score becomes lower.

\section{Discussion}

Among the student population studied, one (1) out of every two (2) students has poor sleep quality. This is similar the prevalence of $50.1 \%$ and $55.8 \%$ reported in previous studies among undergraduate student populations in Nigeria [27] and Ethiopia respectively [16]. This is particularly disturbing considering the negative effect of poor sleep quality on physical and psychological functioning, most especially cognition, of this subset of human population $[6,16,27]$. Our findings indicate that the students reported an average sleep duration of 5.9 hours despite requiring 7-9 hours for optimal functioning [28]. This is 
Table 4. Factors associated with poor sleep quality and academic performance

\begin{tabular}{|c|c|c|c|c|c|}
\hline Variables & Frequency $n=317(\%)$ & Mean PSQI (SD) & Statistics (p value) & Mean CGPA (SD) & Statistics (p value) \\
\hline \multicolumn{6}{|l|}{ Age (in years) } \\
\hline $18-20$ & $111(35.0)$ & $5.95(2.91)$ & $\mathrm{F}=0.25(0.78)$ & $3.68(0.67)$ & $\mathrm{F}=0.94(0.39)$ \\
\hline $21-23$ & $115(36.3)$ & $5.81(3.08)$ & & $3.66(0.57)$ & \\
\hline$>23$ & $91(28.7)$ & $6.12(3.48)$ & & $3.56(0.61)$ & \\
\hline \multicolumn{6}{|l|}{ Gender } \\
\hline Male & $174(54.9)$ & $6.31(3.24)$ & $\mathrm{t}=2.30(0.02)$ & $3.54(0.62)$ & $\mathrm{t}=-3.03(<\mathbf{0 . 0 1})$ \\
\hline Female & $143(45.1)$ & $5.50(2.96)$ & & $3.75(0.60)$ & \\
\hline \multicolumn{6}{|l|}{ Marital status } \\
\hline Single & $308(97.2)$ & $5.92(3.10)$ & $\mathrm{t}=-0.92(0.36)$ & $3.63(0.61)$ & $\mathrm{t}=0.47(0.64)$ \\
\hline Married & $9(2.8)$ & $6.89(4.20)$ & & $3.54(0.75)$ & \\
\hline \multicolumn{6}{|l|}{ Year of study } \\
\hline $1^{\text {st }}$ and $2^{\text {nd }}$ year & $95(30.0)$ & $6.16(2.93)$ & & $3.72(0.62)$ & $\mathrm{F}=1.61(0.19)$ \\
\hline $3^{\text {rd }}$ year & $59(18.6)$ & $6.59(3.28)$ & $F=5.08(<0.01)$ & $3.56(0.62)$ & \\
\hline $4^{\text {th }}$ year & $120(37.9)$ & $5.13(2.81)$ & & $3.65(0.60)$ & \\
\hline $5^{\text {th }}$ and $6^{\text {th }}$ year & $43(13.6)$ & $6.86(3.75)$ & & $3.52(0.66)$ & \\
\hline \multicolumn{6}{|c|}{ Number of courses } \\
\hline$\leq 5$ & $97(30.6)$ & $5.55(3.01)$ & $\mathrm{t}=-1.51(0.13)$ & $3.63(0.66)$ & $\mathrm{t}=-0.21(0.83)$ \\
\hline$>6$ & $220(69.4)$ & $6.12(3.18)$ & & $3.64(0.60)$ & \\
\hline \multicolumn{6}{|c|}{ Carrying over any courses } \\
\hline Yes & $30(9.5)$ & $7.07(3.59)$ & $t=2.07(0.04)$ & $3.18(0.62)$ & $\mathrm{t}=-4.37(<\mathbf{0 . 0 1})$ \\
\hline No & $287(90.5)$ & $5.83(3.07)$ & & $3.68(0.60)$ & \\
\hline \multicolumn{6}{|c|}{ Part time employment } \\
\hline Yes & $55(17.4)$ & $7.07(2.83)$ & $t=2.97(<0.01)$ & $3.61(0.77)$ & $\mathrm{t}=-1.35(0.73)$ \\
\hline No & $262(82.6)$ & $5.71(3.15)$ & & $3.64(0.39)$ & \\
\hline \multicolumn{6}{|c|}{ Sleep duration (hours) } \\
\hline Mean $(\mathrm{SD})$ & $5.9(2.49)$ & & $R=-0.18(0.01)$ & & $\mathrm{R}=0.06(0.31)$ \\
\hline \multicolumn{6}{|c|}{ Routine bed time (hours) } \\
\hline Mean $(\mathrm{SD})$ & $23.34(1.41)$ & & $\mathrm{R}=0.06(0.26)$ & & $\mathrm{R}=0.07(0.22)$ \\
\hline
\end{tabular}

Table 5. Predictors of poor sleep quality and academic performance

\begin{tabular}{|c|c|c|c|c|c|}
\hline \multirow[b]{2}{*}{ Variable } & \multicolumn{2}{|c|}{ Poor Sleep Quality } & \multicolumn{3}{|c|}{ Academic Performance } \\
\hline & AOR & $95 \%$ CI ( $\mathrm{p}$ value) & $\mathrm{B}$ & Statistics (p value) & $95 \% \mathrm{CI}$ \\
\hline Gender & & & 0.12 & $\mathrm{t}=1.77(0.80)$ & $-0.01,3.49$ \\
\hline Male & Reference & & & & \\
\hline Female & 0.84 & $0.50,1.42(0.52)$ & & & \\
\hline \multicolumn{6}{|l|}{ Year of study } \\
\hline $1^{\text {st }}$ and $2^{\text {nd }}$ year & Reference & & & & \\
\hline $3^{\text {rd }}$ year & 0.72 & $0.35,1.50(0.38)$ & & & \\
\hline $4^{\text {th }}$ year & 0.43 & $0.23,0.80(<\mathbf{0 . 0 1})$ & & & \\
\hline $5^{\text {th }}$ and $6^{\text {th }}$ year & 1.39 & $0.61,3.17(0.44)$ & & & \\
\hline Courses carried over & & & 0.4 & $\mathrm{t}=3.51(<0.01)$ & $0.18,0.25$ \\
\hline Yes & 1.03 & $0.41,2.54(0.96)$ & & & \\
\hline No & Reference & & & & \\
\hline \multicolumn{6}{|l|}{ Part-time employment } \\
\hline Yes & 2.67 & $1.34,5.32(<\mathbf{0 . 0 1})$ & & & \\
\hline No & Reference & & & & \\
\hline \multicolumn{6}{|l|}{ Academic performance } \\
\hline $1^{\text {st }}$ class $(4.50-5.00)$ & Reference & & & & \\
\hline $2^{\text {nd }}$ class upper $(3.50-4.49)$ & 3.58 & $1.09,11.71(\mathbf{0 . 0 4})$ & & & \\
\hline $2^{\text {nd }}$ class lower $(2.50-3.49)$ & 7.21 & $2.08,25.00(\mathbf{0 . 0 2})$ & & & \\
\hline $3^{\text {rd }}$ class $(1.50-2.49)$ & 12.04 & $2.41,60.17(\mathbf{0 . 0 2})$ & & & \\
\hline \multicolumn{6}{|l|}{ Perceived stress } \\
\hline $0-9$ & Reference & & & & \\
\hline Oct-15 & 1.92 & $0.69,5.38(0.22)$ & & & \\
\hline $16-20$ & 2.89 & $1.08,7.72(\mathbf{0 . 0 3})$ & & & \\
\hline$>20$ & 3.16 & $1.12,8.92(\mathbf{0 . 0 3})$ & & & \\
\hline Average Sleep duration & 0.76 & $0.62,0.94(\mathbf{0 . 0 1})$ & & & \\
\hline Sleep quality (PSQI score) & & & -0.05 & $\mathrm{t}=5.0(<0.01)$ & $-0.07,-0.03$ \\
\hline
\end{tabular}


similar to the 6.0 hours [29] and 6.2 hours [30] reported from previous studies conducted in the Nigeria. However, it is lower than 6.8 hours reported in a study conducted among 1,845 college students from a State University in southeastern United States [31] and 6.7 hours reported among Korean students [32]. The differences in geographical locations and ethnocultural difference may have accounted for this observation [33].

Among the student population studied, sleep duration did not have a significant association with academic performance although sleep quality had a significant association. Perhaps it is because besides sleep duration, sleep quality takes into account some other components including sleep latency and sleep efficiency whose additive effect could have accounted for this observation. Furthermore, students having extra courses carried over from previous semester had poorer academic performance. This could be because failing a course automatically reduces students' CGPA which was the index used in the measurement of academic performance in this study. Also, failure in academic exams can erode the self-efficacy of students which has been reported to be the strongest single predictor of college students' academic achievement and performance [34].

Students engaged in part-time job were more likely than students without part-time job to have poor sleep quality. This is probably because adding part-time job to academic hassles can potentially increase psychological stress [35] which can worsen the sleep quality. Also, the schedule of this part-time job can affect their sleep pattern as some of they may be working during the night.

In this study, students with good sleep quality had a better academic performance than those with poor sleep quality. This is consistent with observations reported by Curcio, et al. [10] and Adeosun, et al. [20]. This may be because adequate sleep is important for the consolidation of memory $[7,8]$ which is important for academic performance. In addition, that poor sleep might affect certain parts of the brain, especially the frontal and parietal regions including subcortical structures such as basal ganglia and thalamus [36,37]. These structures regulate arithmetic calculation, logical reasoning, attention, decision-making, and planning emotional processing, inhibition control which are very important for good academic performance. This observation might have public health significance because it shows that interventions which can improve sleep quality among undergraduate student population are likely to improve their academic performance.

Perceived stress did not have a significant association with academic performance in this study. This is inconsistent with the studies by Pritchard and Wilson [38] in which they found a significant negative correlation between college stress and academic achievement. However, this observation is similar to the study by Petrie and Stoever [39] in which he reported that life events stress was not a significant predictor of academic performance for sport-major university students. Perhaps the reason for our observation is that the psychometric instrument used to assess stress in this study is too general and non-specific to measure the stress students experience in their academic environment. Further studies could consider using other more specific measures like Stress Scale for College Students [40] and Student Life Stress Inventory [41].

\section{Limitations}

This study was cross-sectional. Thus, it is difficult to ascertain cause and effects among the various factors studied. In spite of this, our findings add to the accumulating evidence that ensuring good sleep quality could enhance academic performance among undergraduate students. Thus, more studies (especially longitudinal) are needed so that policy guidelines can be formulated and implemented to address these factors. In addition, responses by the study participants are subject to recall bias because subjective measures were used in this study. However, these measures have been previously validated before use. Furthermore, generalization of the study findings may be difficult as this study was only carried out in one center. It is recommended that future studies involve multi-centers and in different ethnic populations to address this. Other confounders that could impact cognitive function and academic success including personality, emotional health, learning style, studying skills, time management strategies, diet, exercise, and psychoactive substance use $[42,43]$ were not considered in this study. Future studies can address this.

\section{Conclusion}

This study further emphasizes the relationship between sleep quality and academic performance of undergraduate student. It is therefore imperative to conduct additional research to examine potential causes, implement appropriate measures that can improve sleep quality and treat abnormalities of sleep in this population. This could improve their academic performance.

\section{Funding}

No funding was received for this research

\section{Conflict of interest}

All authors certify that they have no affiliations with or involvement in any organization or entity with any financial interest (such as honoraria; educational grants; participation in speakers' bureaus; membership, employment, consultancies, stock ownership, or other equity interest; and expert testimony or patent-licensing arrangements), or non-financial interest (such as personal or professional relationships, affiliations, knowledge or beliefs) in the subject matter or materials discussed in the manuscript.

\section{Ethical approval}

All procedures performed in studies involving human participants were in accordance with the ethical standards of the institutional and/ or national research committee and with the 1964 Helsinki declaration and its later amendments or comparable ethical standards.

\section{Informed consent}

Informed consent was obtained from all individual participants included in the study.

\section{References}

1. Augustine GJ, Chikaraishi DM, Ehlers MD, Einstein G, Fitzpatrick D, et al. (2004) Neuroscience. Sunderland, Massachusetts USA: Sinauer Associates, Inc.

2. Fafrowicz M, Oginska H, Mojsa-Kaja J, Marek T, Golonka K, et al. (2010) Chronic sleep deficit and performance of a sustained attention task - an electrooculography study. Chronobiol Int 27: 934-944.

3. Wagner U, Gais S, Haider H, Verleger R, Born J (2004) Sleep inspires insight. Nature 427: 352-355. [Crossref]

4. Harrison Y, Horne JA (2000) The impact of sleep deprivation on decision making: review. J Exp Psychol Appl 6: 236-249. [Crossref]

5. Harrison Y, Horne JA (1997) Sleep deprivation affects speech. Sleep 20: 871-877. [Crossref]

6. Diekelmann S, Wilhelm I, Born J (2009) The whats and whens of sleep-dependent memory consolidation. Sleep Med Rev 13: 309-321. [Crossref] 
7. Fogel SM, Smith CT, Cote KA (2007) Dissociable learning-dependent changes in REM and non-REM sleep in declarative and procedural memory systems. Behav Brain Res 180: 48-61. [Crossref]

8. Walker MP, Stickgold R (2004) Sleep-dependent learning and memory consolidation. Neuron 44: 121-133. [Crossref]

9. Buysse DJ, Reynolds CF, Monk TH, Berman SR, Kupfer DJ (1989) The Pittsburgh Sleep Quality Index: a new instrument for psychiatric practice and research. Psychiatry Res 28: 193-213. [Crossref]

10. Curcio G, Ferrara M, De Gennaro L (2006) Sleep loss, learning capacity and academic performance. Sleep Med Rev 10: 323-337. [Crossref]

11. Gilbert SP, Weaver CC (2010) Sleep quality and academic performance in University students: A wakeup call for college psychologists. Journal of College Student Psychotherapy 24: 295-306.

12. Gomes AA, Tavares J, de Azevedo MH (2011) Sleep and Academic Performance in Undergraduates: A Multi-measure, Multi-predictor Approach. Chronobiol Int 28: 786-801. [Crossref]

13. Phillips AC (2013) Perceived Stress. Encyclopedia of Behavioral Medicine. New York: Springer 1453-1454.

14. Acharya S (2003) Factors affecting stress among Indian dental students. $J$ Dent Educ 67: 1140-1148. [Crossref]

15. Shah M, Hasan S, Malik S, Sreeramareddy CT (2010) Perceived stress, sources and severity of stress among medical undergraduates in a Pakistani medical school. $B M C$ Medical Education 10.

16. Lemma S, Gelaye B, Berhane Y, Worku A, Williams MA (2012) Sleep quality and its psychological correlates among university students in Ethiopia: a cross-sectional study. BMC Psychiatry 12.

17. Lazarus RS, Folkman S (1984) Stress, appraisal, and coping. New York: NY: Springer Publishing Company.

18. Ahmed U, Riaz A, Ramzan M (2013) Assessment of Stress and Stressors: A Study on Management Students. IJCRB 4: 687-699.

19. Santen SA, Holt DB, Kemp JD, Hemphill RR (2010) Burnout in medical students: examining the prevalence and associated factors. South Med $J$ 103: 758-763. [Crossref]

20. Adeosun SO, Asa SO, Babalola OO, Akanmu MA (2008) Effects of night-reading on daytime sleepiness, sleep quality and academic performance of undergraduate pharmacy students in Nigeria. Sleep Biol Rhythms 6: 91-94.

21. Bull SB, Pederson LL, Ashley MJ, Lefcoe NM (1988) Intensity of follow-up. Effects on estimates in a population telephone survey with an extension of Kish's (1965) approach. Am J Epidemiol 127: 552-561? [Crossref]

22. James BO, Omoaregba JO, Igberase OO (2011) Prevalence and correlates of poor sleep quality among medical students at a Nigerian university. Ann Nig Med 5: 1-5.

23. Aloba OO, Adewuya AO, Ola BA, Mapayi BM (2007) Validity of the Pittsburgh Sleep Quality Index (PSQI) among Nigerian university students. Sleep Med 8: 266-270. [Crossref]

24. Cohen S, Kamarck T, Mermelstein R (1983) A global measure of perceived stress. $J$ Health Soc Behav 24: 385-396. [Crossref]
25. Tavolacci MP, Ladner J, Grigioni S, Richard L, Villet H, et al. (2013) Prevalence and association of perceived stress, substance use and behavioral addictions: a crosssectional study among university students in France, 2009-2011. BMC Public Health 13.

26. Asani MO, Farouk Z, Gambo S (2016) Prevalence of perceived stress among clinical students of Bayero University Medical School. Niger J Basic Clin Sci 13: 55-58.

27. Seun-Fadipe CT1, Mosaku KS2 (2017) Sleep quality and psychological distress among undergraduate students of a Nigerian university. Sleep Health 3: 190-194. [Crossref]

28. Hirshkowitz M, Whiton K, Albert SM, Alessi C, Bruni O, et al. (2015) National Sleep Foundation updated sleep duration recommendations: final report. Sleep Health 1: 233-243.

29. Chinawa JM, Chukwu BF, Obu HA (2014) Sleep practices among medical students in Pediatrics Department of University of Nigeria Teaching Hospital, Ituku/Ozalla, Enugu, Nigeria. Niger J Clin Pract 17: 232-236. [Crossref]

30. Oluwole OS (2010) Sleep habits in Nigerian undergraduates. Acta Neurol Scand 121 1-6. [Crossref]

31. Gaultney JF (2010) The prevalence of sleep disorders in college students: impact on academic performance. J Am Coll Health 59: 91-97. [Crossref]

32. Ban DJ, Lee TJ (2001) Sleep duration, subjective sleep disturbances and associated factors among university students in Korea. J Korean Med Sci 16: 475-480. [Crossref]

33. Roberts RE, Roberts CR, Chen IG (2000) Ethnocultural differences in sleep complaints among adolescents. $J$ Nerv Ment Dis 188: 222-229. [Crossref]

34. Robbins SB, Lauver K, Le H, Davis D, Langley R, et al. (2004) Do psychosocial and study skill factors predict college outcomes? A meta-analysis. Psychol Bull 130: 261288. [Crossref]

35. Carney C, McNeish S, McColl J (2005) The impact of part time employment on students' health and academicperformance: a Scottish perspective. Journal of Further and Higher Education 29: 307-319.

36. Coull JT (1998) Neural correlates of attention and arousal: insights from electrophysiology, functional neuroimaging and psychopharmacology. Prog Neurobiol 55: 343-361. [Crossref]

37. Goel N, Rao H, Durmer JS, Dinges DF (2009) Neurocognitive consequences of sleep deprivation. Semin Neurol 29: 320-339. [Crossref]

38. Pritchard ME, Wilson GS (2003) Using emotional and social factors to predict student success. JCSD 44: 18-28

39. Petrie TA, Stoever S (1997) Academic and nonacademic predictors of female student athletes' academic performance. JCSD 38: 599-608.

40. Li H (2002) Stress scale for college student. Chinese Journal of Applied Psychology 8: $27-31$.

41. Gadzella BM (1991) Student-life stress inventory. Tx: Commerce.

42. Busato VV, Prins FJ, Elshout JJ, Hamaker C (2000) Intellectual ability, learning style, personality, achievement motivation and academic success of psychology students in higher education. Pers Individ Dif 29: 1057-1068.

43. Lemma S, Berhane Y, Worku A, Gelaye B, Williams MA (2014) Good Quality Sleep is Associated with Better Academic Performance among University Students in Ethiopia Sleep Breath 18: 257-263. [Crossref]

Copyright: (C2017 Seun-Fadipe CT. This is an open-access article distributed under the terms of the Creative Commons Attribution License, which permits unrestricted use, distribution, and reproduction in any medium, provided the original author and source are credited. 